\title{
As DUAS FACES DA CIÊNCIA DE ACORDO COM TOMÁs DE AQUINo
}

\author{
Carlos Arthur Ribeiro do Nascimento ${ }^{12}$
}

\begin{abstract}
Resumo: Tomás de Aquino, ao falar de ciência mostra-se influenciado pelo Segundos analíticos. Entende ciência quer como uma disposiçáo mental, quer como um conjunto de proposiçóes de acordo com as propriedades e relações lógicas e epistêmicas das proposiçōes que dele fazem parte.
\end{abstract}

Palavras Chave: Tomás de Aquino. Filosofia medieval. Ciência. Sujeito da ciência. Objeto da ciência.

\section{NOTA PRÉVIA}

O presente texto foi publicado anteriormente no Boletim do Centro de Estudos do Pensamento Antigo, (jan.-jun.) 1999, p. 73-90 e também em L. A. De Boni (org.). A ciência e a organização dos saberes na Idade Média. Porto Alegre: Edipucrs, 2000. p. 177-190. A razão de publicá-lo novamente provém em primeiro lugar do possível caráter restrito dos dois veículos acima citados: o órgão de um grupo de estudos e as atas de um congresso. Além disso, parece que ainda não há muita clareza sobre a distinção entre "objeto de uma ciência" e "sujeito de uma ciência" tal como é usada por Tomás de Aquino. Em data relativamente recente (2015), um parecerista anônimo de uma revista de filosofia recusava para publicação um texto. Entre seus argumentos para tal, embora nesse texto constem as duas referências acima, havia o seguinte:

\footnotetext{
${ }_{1}^{1}$ Professor Titular Aposentado da Pontifícia Universidade Católica de São Paulo (PUC-SP), São Paulo, SP - Brasil. (D) https://orcid.org/0000-0002-9846-9856 E-mail: carlosartnascimento@gmail.com 2 Professor Titular Aposentado da Universidade Estadual de Campinas (Unicamp), Campinas, SP Brasil.
}

http://dx.doi.org/10.1590/0101-3173.2019.v42esp.04.p57 
A fidelidade à letra do texto peca por excesso, ao traduzir literalmente por "sujeito" ou por "género-sujeito" (pp. 2-4, 8-11) o termo subiectum, que significa o género do objeto da ciência. Assim, o artigo não só não adopta a tradução utilizada e anexada, que dá, preferivelmente, o mesmo termo por "tema", como se presta a equívocos de leitura, uma vez que emprega "sujeito" e "género-sujeito", num sentido completamente arredado do uso quer filosófico quer corrente do termo "sujeito" na actualidade. A explicação dada no $2^{\circ}$ parágrafo da p. 3 procura esclarecer a opção por "género-sujeito", mas não anula a estranheza e a equivocidade desta opção nas restantes ocorrências. Deve, pois, ser revisto o uso do termo "sujeito" e da expressão "género-sujeito" ao longo do artigo.

Ao iniciar o capítulo dedicado à "ciência demonstrativa" na The Cambridge History of Later Medieval Philosophy, Eileen Serene diz que “a expressão 'ciência demonstrativa' é ambígua, referindo-se tanto ao conhecimento que um silogismo desmonstrativo produz em alguém que o entende quanto a um sistema de silogismos compreendendo proposiçóes que satisfaçam os requisitos para a demonstração, estipulados nos Segundos analíticos de Aristóteles" (1985, p. 496). A validade desta observação no que se refere a Tomás de Aquino é apontada por Scott Mac Donald no capítulo sobre "teoria do conhecimento" do The Cambridge Companion to Aquinas. Lemos aí que:

Para Tomás de Aquino, que segue de perto os Segundos analiticos nestes assuntos, scientia pode designar um tipo de estado ou disposiçáo mental - o que poderíamos chamar de uma atitude proposicional; mas, pode designar também um conjunto de proposiçóes organizado por assunto [subject matter] e de acordo com as propriedades e relaçóes lógicas e epistêmicas das proposiçóes que dele fazem parte - o que poderíamos chamar de um corpo organizado de conhecimento [knowledge], de uma teoria ou de uma ciência. (MAC DONALD, 1996, p. 188-189, n. 13).

Encontramos, de fato, esta dupla consideração da ciência (ou, de maneira mais geral, do conhecimento) indicada numa série de textos de Tomás que se escalonam desde seu primeiro ensino parisiense (1252-1259) até sua segunda estadia em Paris (1268-1272), passando por seu ensino em Roma (1265-1268). Datam da época do primeiro ensino parisiense uma passagem do Escrito sobre as Sentenças (livro III, distinçáo VIII, artigo 5, resposta ao 
$5^{\circ}$ argumento da $1^{\text {a }}$ série inicial), um trecho das Questóes disputadas sobre a verdade (questáo 3, artigo 3 - Leonina 22, 1, 2, p. 108, lin. 148-174) e um artigo da Questão quodlibetal VII (questão 1, artigo 4 - Leonina 25, I, p. 15, lin. 22-16, lin. 58). Pertencem ao período romano duas passagens das Questóes disputadas sobre o poder de Deus (questão 7 , artigo 5, resposta ao $9^{\circ}$ argumento da $1^{\text {a }}$ série; questão 8 , artigo 2). Finalmente, interessa-nos o que é dito na Sentença do livro da Metafísica (livro V, n. 1028-1029) que é da época de sua segunda estadia em Paris ${ }^{3}$.

É de se notar que estes textos cobrem praticamente toda a carreira intelectual de Tomás de Aquino, apresentando de maneira constante a mesma postura. Os contextos em que a distinção entre a ciência como conhecimento possuído por alguém e a ciência como conjunto de proposiçóes é evocado podem ser reduzidos basicamente a dois. De um lado temos textos que se referem mais diretamente ao estatuto ontológico da relação, que, à diferença dos demais acidentes, diz respeito enquanto relação (ad aliquid), não ao seu sujeito de inerência, mas a algo de outro. Podemos considerar como pertencentes a este contexto as passagens citadas dos Escritos sobre as Sentenças, da questão 8 das Questôes sobre o poder de Deus e da Sentença da Metafísica. Aliás, os dois primeiros textos remetem ao trecho do livro V da Metafísica (1021a29-33) comentado no terceiro. Este último é uma observação pessoal de Tomás de Aquino, introduzida pela cláusula canônica "Ora, é preciso saber que..." (Sciendum est autem quod...) ${ }^{4}$, e póe em relevo o exemplo da ciência evocado por Tomás nos dois outros textos. Citemos esta passagem da Sentença da Metafísica:

Ora, é preciso saber que, embora a ciência, no que respeita ao nome, pareça referir-se ao cognoscente e ao cognoscível, pois é dita ciência do cognoscente e ciência do cognoscível, e a intelecção ao inteligente e ao inteligido, a intelecção, na medida em que é dita "para algo", náo é dita para isto, do qual é como de um sujeito; seguir-se-ia, com efeito, que o

${ }^{3}$ Utilizamos as seguintes edições dos textos de Tomás de Aquino: Scriptum super Sententiis. Paris: Lethielleux, 1929, Tomo I, Ed. P. MANDONNET; 1956, Tomo III, Distinção I-XXI, Ed. M. F. MOOS; "Quaestiones disputatae de veritate". In: Sancti Thomae de Aquino opera omnia. Roma: Commissio Leonina, 1970, Tomo 22, 1, Fasc. 2; "Expositio Libri Posteriorum”. In: Ibidem, 1989, Tomo I, 2, Ed. Altera retractata; "Quaestiones de quodlibet". In: Ibidem, 1996, Tomo 25, 1; "Qaestiones disputatae de potentia”. In: Quaestiones disputatae. Turim: Marietti, 1953, v. 2, p. 7-276; Summa Theologiae. Roma: Editiones Paulinae, 1962; In duodecim libros Methaphysicorum Aristotelis expositivo. Turim: Marietti, 1950.

${ }^{4}$ Acerca da identificação nos comentários de Tomás de Aquino das passagens que não se restringem a estabelecer o sentido do texto comentado, mas exprimem o pensamento do comentador, ver (GEIGER, 1957, p. 177). 
mesmo fosse dito relativo duas vezes. De fato, isto é certo, pois a intelecção é para o inteligível como para o objeto. Se fosse, porém, dita para o inteligente seria dita "para algo" duas vezes; ora, visto o ser do relativo ser o "estar de um certo modo para outro", seguir-se-ia que o mesmo tivesse um duplo ser. Isto é igualmente patente acerca da vista, que não é dita para o vidente, mas para o objeto que é a cor "ou algo de outro que tal", o que diz por causa do que é visto à noite, não pela própria cor como se encontra no livro II Sobre a alma (7, 418a26 e 419a3). Embora isto também pudesse ser dito corretamente, isto é, que a vista é do vidente; a vista refere-se ao vidente não na medida em que é vista, mas na medida em que é um acidente ou potência do vidente. Com efeito, a relação visa algo fora, não porém o sujeito, a não ser na medida em que é acidente. Fica, assim, patente que estes são os modos de acordo com os quais algo é dito por si mesmo "para algo"

O segundo contexto em que as duas maneiras de considerar a ciência (como acidente de um sujeito ou como referida a um objeto) aparece diz respeito ao conhecimento, seja ele o conhecimento divino (em que medida podemos falar de ideias ou de sabedoria divinas), seja ele conhecimento humano (Tomás procura situar a "notícia" de que fala Agostinho em relação à "mente"). Tanto ideia como sabedoria ou notícia podem ser consideradas sob dois aspectos:

Ou na medida em que se compara ao cognoscente, e deste modo, inere ao cognoscente como o acidente no sujeito, e deste modo, náo excede o sujeito, pois nunca se dá que inira a algo senão à mente. Ou na medida em que se compara ao cognoscível, e por esta parte, não lhe advém que inira (esteja em), mas que seja para outro. Ora, o que é dito para outro náo reveste a determinaçáo de acidente a partir do fato de que é para outro, mas apenas a partir do fato de que inere, vindo daí que apenas a relação, de acordo com a determinaçáo do seu gênero, permanece com a substância no divino, não sendo aí, porém, acidente ${ }^{6}$.

O início deste último texto nos permite ainda supor que a ciência, na medida em que é um acidente num sujeito (o cognoscente), deve amoldarse às condiçóes de conhecimento deste sujeito. Seria preciso então estudar

\footnotetext{
${ }^{5}$ A última frase finaliza a explicação iniciada no no 1006 e que apresenta três tipos de relação: de acordo com o número e a quantidade, de acordo com a ação e a recepção e enfim de acordo com a medida.

${ }^{6} \mathrm{O}$ trecho citado é da Questão quodlibetal VIII, q. 1, a. 4, Leonina, 25, 1, p. 16, lin. 37-48. Consideramos como pertencendo também a este contexto as passagens mencionadas das Questôes disputadas sobe a verdade e o trecho da questão 77, artigo 5 das Questóes disputadas sobre o poder de Deus.
} 
em primeiro lugar como Tomás de Aquino apresenta o processo de sua aquisição com base nas características próprias do intelecto humano. São as possibilidades deste que permitirão explicar como a ciência é adquirida e como se organiza uma vez adquirida. Tomás de Aquino examina esta questão de um ponto de vista mais amplo, isto é, como o conhecimento intelectual é adquirido nas questôes 85-89 da primeira parte da Suma de teologia, questóes estas que supóem o que se disse anteriormente (questão 79) sobre a natureza do intelecto humano. Sáo particularmente importantes do nosso ponto de vista as questóes 84-86, que tratam do conhecimento intelectual dos corpos. Aí se expóe como nosso intelecto não conhece as coisas materiais por se autoconhecer, mas através de determinaçôes inteligíveis (species intelligibiles) que não lhe são inatas, nem lhe advêm de formas separadas (como sustenta Platão) nem de uma inteligência agente separada (como pensava Avicena), mas devem ser "recebidas dos sentidos à maneira de uma certa abstração" (segundo a tese de Aristóteles) (Suma de teologia, Ia, q. 84, a. 6); como a apreensão de nosso intelecto é imperfeita e parcial, deriva daí a necessidade de compor e dividir formando enunciados e também a necessidade de raciocinar indo de um enunciado a outro (Suma de teologia, I', q. 85, a. 5 e 6).

Passamos por alto tudo isso, contentando-nos em simplesmente reafirmar o que foi sumariamente apesentado, isto é, que na origem do conhecimento científico está a "experiência" que nos fornece o material a partir do qual formamos (por abstração) os conceitos que compomos e dividimos ao julgar.

Estudaremos um pouco mais detalhadamente a ciência já adquirida, isto é, a ciência in facto esse por oposição à ciência in fieri, no seu processo de aquisição. Como já adquirida, podemos considerá-la como ato e como hábito. Como ato, supondo a definição aristotélica de ciência ${ }^{7}$, ela é o conhecer atual das conclusóes em dependência das premissas que as demonstram.

Como hábito, trata-se de uma qualificação estável do intelecto. É o que passamos a expor de modo mais detalhado, valendo-nos do que é proposto pelo Cardeal Cajetano (Tomás de Vio) em seu comentário à Suma de teologia de Tomás de Aquino ( $\mathrm{I}^{\mathrm{a}} \mathrm{II}^{\mathfrak{x}}$, q. 54, a. 4) ${ }^{8}$. Cajetano diz, a propósito da resposta ao

\footnotetext{
${ }^{7}$ II Anal. I, 2, 71b9-10: "Arbitramos possuir a ciência absoluta de algo e não, ao modo dos sofistas, de um modo acidental, quando julgamos que conhecemos a causa pela qual esse algo é, quando sabemos que essa é a causa desse algo, e quando, além disso, não é possível que esse algo seja outro que não este." [Tradução Pinharanda Gomes, Organon, v. IV (Analiticos Posteriores). Lisboa: Guimarães Ed., 1987].

${ }^{8}$ Sancti Thomae Aquinatis, Opera omnia, tomus VI, I ${ }^{a} \mathrm{II}^{x}$ Summae theologiae, q. 1-70, Cum Commentariis Thomae de Vio Cajetani. Romae: Typographia Polyglotta S. C. de Propaganda Fide,
} 
terceiro argumento inicial ( $\mathrm{ad} 3 \mathrm{~m})$, que há uma discussão frequente, seja entre os discípulos de Tomás de Aquino, seja entre estes e outros ${ }^{9}$, acerca do hábito científico: seria ele constituído por um conjunto ordenado de determinações inteligíveis (species intelligibiles) referentes a uma certa razão formal do objeto cognoscível cientificamente ou seria uma qualidade simples habilitando a lidar com tais determinaçóes inteligíveis rápida, fácil e prazerosamente, de acordo com as exigências do assunto em pauta? Cajetano não crê que Tomás, ora se incline para o primeiro ponto de vista, ora para o segundo, dando mais ênfase ao primeiro. De acordo com ele "a doutrina de Santo Tomás é que o hábito de ciência é uma qualidade simples que se estende a todas as conclusóes que dizem respeito à mesma razão mais particular (ratio specialissima) sob o gênero do cognoscível cientificamente" ( $\left.\mathrm{n}^{\circ} \mathrm{V}\right)$.

A explicação e justificação desta tese é apresentada nos números VI e VII do comentário. Com efeito,

é preciso conceder que uma certa ciência como hábito especificamente una, como por exemplo, a geometria, estabelece duas coisas no nosso intelecto. A primeira são as determinaçôes inteligíveis das linhas, ângulos, figuras etc.; a segunda é a habilitação para considerar rápida, fácil e prazerosamente as conclusóes cientificamente conhecidas na geometria. Ora, que seja preciso estabelecer determinaçôes inteligíveis ordenadas em vista de uma e mesma razão formal de tal cognoscível cientificamente é patente pelo fato de que vários de acordo com a espécie não se congregam em um de acordo com a espécie, a não ser ordenados de alguma modo a este uno, como é patente na pluralidade de heterogêneos tanto no que é natural como no que é artificial. De fato, como as determinaçóes inteligíveis do sujeito, por exemplo da Lua, e a determinaçáo do acidente, por exemplo do eclipse, e a determinação da causa intermediária, por exemplo da Terra interposta, etc. congregam-se em um ato especificamente uno de conhecer cientificamente, a não ser ordenadas? Por outro lado, como todas as determinaçóes inteligíveis de todas as coisas contidas sob uma espécie de cognoscível cientificamente como tal congregam-se, a não ser de algum modo ordenadas? De fato, "onde há pluralidade sem ordem, há aí confusão”. - Que, porém, seja exigida alguma habilitação para lidar rápida, fácil, etc. com estas determinaçôes assim ordenadas é patente pelo próprio fato de que o intelecto, sendo por si uma "tabula rasa”, não é por si ordenado a tal uso do que é assim determinado a um cognoscível cientificamente uno, mas é preciso que seja determinado por

1891, p. 345-348. Supomos que a interpretação de Cajetano seja correta, o que, no entanto, não é evidente e, a rigor, deveria ser mostrado.

${ }^{9}$ Cajetano menciona no início do no IV de seu comentário, Pedro Auriol (c. 1280-1322) e Gregório de Rimini (c. 1300-1358). 
alguma qualidade a ele acrescentada e que vise por si primeiramente a este cognoscível cientificamente, para lidar rápida, fácil e prazerosamente com quaisquer determinaçóes inteligíveis e atos ordenados a este. Ora, consta que esta qualidade habilitante e una, de acordo com a unidade de seu objeto, e, por isso, de uma espécie a mais particular, é, por conseguinte, uma qualidade simples, visto ser uma espécie de qualidade.

Cajetano observa que, estando presentes no intelecto o conjunto ordenado de determinaçóes inteligíveis e a habilitação para lidar com elas, resta determinar qual dos dois reveste a razão essencial, não de hábito, mas de tal hábito, isto é, da ciência humana que é um hábito adquirido pela demonstração. Observa ainda que disse de propósito "não de hábito", pois consta que as determinaçôes inteligíveis são, para Santo Tomás, hábitos intelectuais; disse também propositadamente "da ciência humana", pois consta que nos anjos o hábito de ciência são apenas as determinações inteligíveis.

O número VII vai estabelecer que a ciência humana é essencialmente a qualidade simples já referida:

Ora, que a ciência de que falamos não é essencialmente as várias determinaçóes inteligíveis ordenadas, mas a qualidade simples, é manifesto pelo fato de que o hábito científico está essencialmente na primeira espécie de qualidade como uma de suas espécies mais particulares.

Consta, com efeito, que nenhuma espécie de qualidade é composta de várias qualidades de espécies distintas como o são as determinações inteligíveis. Portanto, ou neguem que o hábito de ciência é essencialmente uma certa espécie no gênero da qualidade, sustentando que ela é una quanto à ordem, como um exército e formalmente no gênero da relação e só materialmente no gênero da qualidade, o que repugna a toda a doutrina deste tratado (dos hábitos); ou concedam que ela não é formalmente as determinaçôes inteligíveis, mas uma qualidade simples para lidar com estas.

Pode-se, portanto, dizer que o intelecto humano possui perfeitamente uma ciência quando tem, numa ordem conveniente, as determinaçóes inteligíveis que dizem respeito à matéria de que trata esta ciência; quando, além disso, possui uma qualificação que o habilite a lidar com estas determinaçóes inteligíveis e a dispô-las na ordem conveniente já mencionada. Tal qualificação constitui essencialmente o hábito científico. Ela torna o intelecto apto a ordenar as determinaçôes inteligíveis e a lidar com elas pronta, fácil e prazerosamente porque se refere própria e primeiramente à razão formal do objeto cognoscível 
cientificamente que especifica e confere unidade a este objeto. Então, por referir-se própria e primeiramente a esta razão formal, é apta a ordenar por referência a esta as determinaçôes inteligíveis ${ }^{10}$.

Temos, deste modo, uma descrição da ciência como qualificação do intelecto humano. Se tomarmos as determinaçóes inteligíveis de que falamos podemos considera-las não só como inerentes ao intelecto, mas como presença das coisas no intelecto. Esta é a consideração da ciência, do ponto de vista do cognoscível $^{11}$. Os elementos que a constituem serão justamente aqueles que permitem esta presença da coisa no intelecto. Ora, algo só pode estar presente no intelecto na medida em que não for incomunicável. Tomás de Aquino sustenta que a incomunicabilidade no caso das coisas materiais se liga à matéria ${ }^{12}$. Daí as coisas materiais deverem estar presentes no intelecto despidas da matéria e das condiçóes materiais individualizantes (Suma de teologia, Ia, q. 84 , a. 2) ${ }^{13}$. Em outros termos: devem aí estar presentes como universais. No caso do conhecimento científico é preciso ainda lembrar que estarão presentes no intelecto apenas os elementos necessários da coisa. Donde o conhecimento científico dizer respeito ao imaterial, universal e necessário. Daí também conter ele a essência da coisa expressa na definição e as propriedades necessariamente decorrentes desta essência. Assim, a estrutura básica do conhecimento científico se apresentará como uma série de demonstrações tendo como termo médio a definição do "sujeito" de tal ciência (termo menor) e as propriedades necessárias como termo maior. $\mathrm{O}$ papel da demonstração será justificar como tais propriedades se ligam ao "sujeito". Dizendo o mesmo em termos de proposiçôes: a ciência, da parte do cognoscível, apresenta-se como um conjunto de demonstraçóes em que as conclusóes são justificadas pelas premissas (princípios) ${ }^{14}$.

\footnotetext{
${ }^{10}$ Cajetano trata ainda no seu comentário de três tópicos: a relação da qualidade simples com o conhecimento das diversas conclusōes de uma ciência ( $n^{\circ}$ VIII); as quatro relaçóes da qualidade simples com as determinações inteligíveis ( $\mathrm{n}^{\circ} \mathrm{IX}$ ); resposta aos argumentos dos que sustentam a opinião de que a ciência é essencialmente constituída pelas determinaçôes inteligíveis ( $\mathrm{n}^{\circ} \mathrm{X}-\mathrm{XVI}$ ).

${ }^{11}$ Falamos aqui da ciência humana e do seu domínio conatural, as coisas materiais. Não se pretende apresentar a ciência e o conhecimento em toda sua amplidão. Cf. (ROBERT, 1957, p. 443-469).

${ }^{12}$ Não é possível retomar aqui a teoria da individuação das substâncias materiais, de acordo com Tomás de Aquino. Cf. (BOBIK, 1953, p. 5-41; MORRIS, 1996, p. 321-333, 338).

${ }^{13}$ Trata-se de uma exigência também da parte do intelecto, pois, segundo Tomás, este é imaterial.

${ }^{14}$ Tomás de Aquino retoma a teoria da ciência dos Segundos analíticos como se disse desde o início. Cf. (MAC DONALD, 1996, p. 188-189).
} 
A terminologia "objeto" e "sujeito" de ciência está ligada à dupla consideração da ciência de que se falou anteriormente. Há uma curta declaração de Tomás de Aquino na Suma de teologia ( $\mathrm{I}^{\mathrm{a}}$, q. 1, a. 7) que costuma ser citada neste contexto:

Sic enim se habet subjectum ad scientiam sicut objectum ad potentiam vel habitum.

De fato, o sujeito está para a ciência assim como o objeto está para a potência ou o hábito.

Afirma-se, pois, que o papel do sujeito em relação à ciência é semelhante ao do objeto em relaçáo à potência ou ao hábito. Um pouco mais adiante, no mesmo artigo da Suma, Tomás de Aquino faz uma observação que esclarece um pouco mais acerca do sujeito da ciência:

Idem autem est subjectum principiorum et totius scientiae, cum tota scientia virtute contineatur in principiis.

Ora, o sujeito dos princípios é o mesmo que o de toda a ciência visto que toda a ciência está contida virtualmente nos princípios.

Dito em outros termos: o sujeito da conclusão é o mesmo da premissa menor, uma vez que o princípio próprio da demonstração é a definição do sujeito, usada como termo médio. Tomás de Aquino está então apontando claramente para a ciência concebida como sistema de demonstraçóes ${ }^{15}$.

Para melhor compreensão, retomemos um pouco mais detalhadamente a relação do objeto com o hábito e do sujeito com a ciência. Tomás sustenta que os hábitos, considerados precisamente como tais, se especificam e distinguem de acordo com seus objetos (cf. Suma de teologia, $\mathrm{I}^{\mathrm{a}} \mathrm{II}^{x}$, q. 54, a. 2). Ora, como vimos, a ciência considerada da parte do cognoscente é um hábito cujo elemento essencial é uma qualificação simples. O que é visado por esta qualificação, seu objeto, é o conjunto ordenado de determinaçôes inteligíveis. Mais precisamente, esta coleção de determinações inteligíveis se apresenta

\footnotetext{
15 Convém notar que o desconhecimento da não-coincidência entre sujeito e objeto leva a não entender o texto de Tomás de Aquino. Por exemplo, a traduçáo brasileira de A. CORREIA (1946, v. 1, p. 46-47) estropia completamente a passagem referida: "O objeto está para a ciência como para a potência ou hábito [...] Ora, idêntico objeto têm os princípios e toda a ciência, por estar a última, total e virtualmente contida nos primeiros." Mesmo um estudioso táo atento como H. D. GARDEIL pode escrever uma nota nada esclarecedora (1997, p. 70, nota 16).
} 
como constituída por proposiçóes que dizem respeito a um sujeito, isto é, conclusóes apoiadas em suas razões demonstrativas (termo médio, definição do sujeito).

É nesta perspectiva que Tomás de Aquino distingue as três virtudes intelectuais teóricas ou especulativas: o hábito dos primeiros princípios, a sabedoria e a ciência. A primeira tem como objeto o verdadeiro evidente por si mesmo que se exprime em proposiçóes evidentes por si mesmas (primeiras e imediatas); a segunda e a terceira têm como objeto o verdadeiro mediatamente evidente que se exprime em proposiçóes dotadas de evidência mediata, isto é, que devem ser demonstradas (Suma de teologia, $\mathrm{I}^{\mathrm{a}} \mathrm{II}^{x}$, q. 57, a. 2) ${ }^{16}$.

Uma distinção importante é a que Tomás estabelece entre o objeto material e a razão formal do objeto ${ }^{17}$. A mesma proposição mediata, materialmente considerada, pode ser objeto de várias ciências. Um exemplo que Tomás de Aquino cita com frequência é a proposição "a Terra é redonda" 18 , que pode ser objeto da astronomia e da física, conforme a razão formal do objeto (compendiada no termo médio do silogismo) for de ordem matemática (por exemplo, as sombras projetas pela Terra durante um eclipse são redondas) ou física (por exemplo, todos os corpos graves tendem para o centro). Tomás se servirá desta distinção para situar o objeto da fé teologal (Suma de teologia, $\mathrm{II}^{\mathrm{a}} \mathrm{II}^{x}$, q. 1 , a. 1 e 2). É a razão formal do objeto que é visada em primeiro lugar pela qualificação simples constitutiva do hábito científico; é através desta razão formal que a qualificação simples visa as proposições que fazem parte de uma ciência específica. É, pois, a razão formal do objeto que dá unidade a uma ciência como hábito.

Coloquemo-nos agora do ponto de vista do que é conhecido. As proposiçóes que constituem a ciência dizem respeito a algo, detalham as propriedades de um sujeito. Aqui também podemos distinguir o sujeito

\footnotetext{
${ }^{16}$ Neste artigo, Tomás de Aquino, além de distinguir o hábito dos princípios da sabedoria e ciência, distingue também a sabedoria da ciência, indica a razão da unicidade da sabedoria e da multiplicidade das ciências, como as proposições evidentes por si mesmas são objeto do hábito dos princípios e da ciência, como outros hábitos ou disposições intelectuais (opinião, suspeita) não são virtudes propriamente ditas e como se relacionam as três virtudes intelectuais.

${ }^{17}$ Cf. (Suma de teologia, $\mathrm{I}^{\mathrm{a}}$, q.77, a. 3; $\mathrm{I}^{\mathrm{a}} \mathrm{II}^{x}$, q. 54, a. 2, ad 1m; q. 57, a. 2, arg. 2 e ad 2m). Ver também o Comentário ao Tratado da Trindade de Boécio, q. 5, a. 1; Expositio Libri Posteriorum, I, 41, p. 154-155, lin. 242-300.

${ }^{18}$ Cf. In II Sentenças, dist. 24, q. 2, a. 2, ad 5m; In Sobre a Trindade de Boécio, q. 5, a. 3, ad 7m; Suma de teologia, $\mathrm{I}^{\mathrm{a}}$, q. 1, a. 1, ad 2m; Comentário à Física, II, liçấo 3, no 9; Suma de teologia, $\mathrm{I}^{\mathrm{a}} \mathrm{II}^{\mathrm{x}}$, q. 54, a. 2, ad 2m. Ver também, Nascimento (1998, p. 25-26).
} 
material e a razão formal do sujeito. No exemplo da proposição "a Terra é redonda", o sujeito material é a Terra, isto é, aquilo de que a ciência trata, sem maiores precisôes. A Terra pode ser sujeito de várias ciências neste sentido; por exemplo, da astronomia e da ciência da natureza. Ou então, a mesma ciência pode ter diversos sujeitos materiais; por exemplo, a voz humana e os sons produzidos por corpos inanimados são tratados pela mesma ciência, a acústica (música). A razão formal do sujeito é fornecida pelos princípios de conhecimento (modo de definir). Neste sentido, algo pode constituir uma única coisa com outra e, no entanto, ser sujeito de uma ciência distinta. Tomás exemplifica com o corpo matemático em relação ao corpo natural:

O corpo matemático não está substancialmente separado do corpo natural, mas, como o corpo matemático é conhecido pelos princípios da quantidade e o corpo natural pelos princípios do movimento, a geometria e a ciência natural não são a mesma ciência ${ }^{19}$.

Uma tríplice relação situa o sujeito considerado formalmente em relação à ciência: 1) tudo de que se trata na ciência deve estar contido sob o sujeito, que funciona como um todo universal; 2) o que é buscado principalmente na ciência é o conhecimento do seu sujeito - daí este se portar como o fim da ciência; 3) o sujeito unifica a ciência e a distingue das demais ${ }^{20}$.

19 Si uero alique sint eadem secundum naturam et tamen per diuersa principia considerentur, manifestum est quod ad diversas scientias pertinent; sicut corpus mathematicum non est sepratum subjecto a corpore naturali, quia tamen corpus mathematicum cognoscitur per principia quantitatis, corpus autem naturale per principia motus, non est eadem scientia geometria et naturalis. Expositio Libri Posteriorum (I, 41, p. 155, lin. 262-270).

${ }^{20}$ Cf. In I Sentenças, prólogo, q. 1, a. 4: "Subjectum habet ad scientiam ad minus tres comparationes. Prima est quod quaecumque sunt in scientia debent contineri sub subjecto. Secunda comparatio est quod subjecti cognitio principaliter intenditur in scientia. Tertia comparatio est, quod per subjectum distinguitur scientia ab omnibus aliis, quia secantur scientiae quemadmodum et res ut dicitur in III De anima." Alberto Magno menciona também as duas primeiras relaçôes: "Subjectum est in scientia, ad quod sicut ad commune praedicatum reducuntur partes et differentiae, quarum quaeruntur proprietates in ipsa, et ad quod consequuntur passiones, quae inesse subjecto demonstratur." (Methaphysica, liv. I, tratado I, cap. 2; Ed. Geyer, p. 3, Col. B, lin. 101-108). Cf. (COURTINE, 1990, p. 101-108). O próprio Tomás de Aquino refere-se à segunda relação no prólogo do seu comentário à Metafísica: "Hoc enim est subjectum in scientia, cujus causas et passiones quaerimus, non autem ipsae causae alicujus generis quaesiti." Para o papel de fim do sujeito ver Expositio Libri Posteriorum (I, 41, p. 153, lin. 131-153).

Discordamos, pois de Maurer (1958, p. 98-112), que sustenta que a "distinçâo tomista entre sujeito e objeto de uma ciência é completamente diferente da de Ockham” (p. 107). A explicação de Maurer que se segue (p. 107-108) caracterizando "o sujeito de uma ciência como o fim ou término do processo da ciência” não parece suficientemente clara. Cremos, ao contrário de Maurer (p. 99), que a distinção entre 
É importante acentuar o primeiro aspecto - o sujeito é um todo universal ou, como se expressa Tomás de Aquino, um genus scibile ou genus subjectum (Exp. Lib. Posteriorum, I, 41, p. 153-155, lin. 107-318). Se houvesse uma adequação perfeita entre nosso conhecimento e as coisas, cada essência individualmente considerada fundamentaria uma ciência, sendo a definição de tal essência a razão explicativa dos predicados próprios que lhe cabem. $\mathrm{O}$ caráter abstrativo de nosso conhecimento intelectual implica, não só que não temos ciência do individual ${ }^{21}$, mas também que certos grupos de ciências formam como que áreas de conhecimento dotadas de um sujeito formal comum. É assim que as ciências teóricas serão divididas em três: física (ciência da natureza), matemática e metafísica (filosofia primeira, teologia). Tomás de Aquino mostra de maneira minuciosa como os genera scibilia destas três áreas têm um fundamento nas próprias coisas e são obtidos por operaçóes características de nosso intelecto, genericamente denominadas abstração ${ }^{22}$. Cada um destes genera scibilia é expresso numa definição que comporta elementos diferenciados conforme se trate do sujeito da física, da matemática ou da metafísica. É esta definição que, falando ainda de modo geral, servirá de termo médio nas demonstraçóes de cada uma destas ciências ${ }^{23}$.

É possível ainda, a propósito dos sujeitos considerados formalmente ou a propósito dos genera scibilia, distinguir o sujeito comum (o genus scibile) considerado em toda sua extensão e o sujeito principal - aquilo em que este gênero se realiza por excelência e cujo conhecimento é buscado principalmente. Tomás explicita esta distinção a propósito da metafísica: "Ora o sujeito desta ciência (metafísica) pode ser tomado, seja como e considerado de maneira comum em toda a ciência, modo pelo qual ele é o ente e o uno; seja como o que é principalmente visado, como a substância" ${ }^{24}$.

Tendo em conta o que dissemos sobre o objeto e o sujeito da ciência, podemos verificar que há correspondência entre a razão formal do objeto e o sujeito considerado formalmente: ambos devem sua determinação à definição do sujeito que serve como termo médio demonstrativo. Assim sendo, a

sujeito e objeto de uma ciência não foi "adotada", a partir de Ockham, por alguns tomistas. Ela já estava presente em Tomás de Aquino, certamente não de maneira inteiramente explicitada e sistematizada.

${ }^{21}$ Não temos sequer conhecimento intelectual direto do individual. Cf. Suma de teologia (I ${ }^{a}$, q. 84, a. 7 e q. 86, a. 1). Ver também (KLUBERTANZ, 1952, p. 135-165).

${ }^{22} \mathrm{O}$ texto em que Tomás de Aquino analisa a divisão tripartida das ciências teóricas de maneira mais detalhada é o Comentário ao Tratado da Trindade de Boécio, q. 5 e 6.

${ }^{23}$ Expressa-se assim um ideal dificilmente atingível. Cf. (NASCIMENTO, 1996, p. 207-208).

${ }^{24}$ In Metaphysicam, liv. V, lição 7, no 842. Cf. Suma contra os gentios, liv. I, cap. 70, $1^{\circ}$ patet. 
especificação da ciência pela razão formal do objeto coincide com a que lhe advém pelo sujeito formal. $\mathrm{O}$ que, no entanto, não autoriza a misturar as duas perspectivas de análise e os seus vocabulários respectivos. Há ainda, nesta linha, uma última consideração importante: se considerarmos o sujeito tomado formalmente e as conclusóes à luz da razão formal do objeto, isto é, o objeto formal, ambos devem afinal se recobrir, pois as conclusōes nada mais são que a explicação das propriedades do sujeito formal; mas, dado o caráter progressivo de nosso saber, nunca o objeto formal recobrirá completamente as propriedades do sujeito formal, quer dizer, suas virtualidades inteligíveis.

Numa minuciosa resenha do livro de Jean-François Coutine sobre Suarez et le système de la métaphysique (Paris, P.U.F., 1990), H. C. De Lima Vaz tece algumas consideraçóes que têm a ver com a questáo aqui exposta. Referindo-se à "virada (tournant) suareziana", sustenta que esta define-se a partir de motivos teóricos fundamentais estudados por Courtine. O primeiro destes é assim indicado:

No domínio noético-metodológico opera-se a substituição definitiva da doutrina aristotélica do subjectum scientiae fundada sobre a pressuposiçáo de relaçáo imediata da inteligência com o ser (intellectus in actu est intellectum in actu) pela concepção de um objectum scientiae cujas origens devem ser buscadas em Avicena e no contemporâneo de Tomás de Aquino, Henricus Gandavensis (Henri de Gand) mas que, elaborada amplamente por D. Escoto e pela escola escotista, estará presente na questão inicial de Suárez: quod sit Metaphysicae objectum. Tal concepçáo do objectum scientiae assinala, de fato, o triunfo definitivo, no domínio da Metafísica, da representaçáo sobre o ser ou do esse objectivum sobre o esse in re, que prevalece em toda a filosofia moderna. (VAZ, 1994, p. 401).

Tendo em conta o complexo percurso histórico, relembrado pelo Pe. Vaz, apenas no que diz respeito ao uso das expressóes subjectum scientiae e objectum scientiae, talvez haja aí matéria para ulteriores pesquisas. Com efeito, este percurso histórico entre os séculos XIII e XVII pode se revelar menos linear do que poderia parecer. Reunimos aqui apenas algumas indicaçóes que, como acabamos de dizer, talvez mereçam maior aprofundamento.

Comecemos por uma referência a Aristóteles e Avicena, simplesmente transcrevendo uma nota de J. Owens (1957, p. 36, n. 10):

Aristotle does not speak of the 'object' of science. He merely names what the science treats, either in the accusative case after a verb, or in the genitive after a noun; or, more frequently, with the preposition 'about'. 
The Arabians - in accord with their general usage of the passive participle for the object of any activity - employed the participle MAWDUc, meaning 'that which is posited'. This was the same term which they used for the subject of predication (cf. A.-M. Goichon, Lexique, pp. 438-439; Vocabulaires, p. 40a). The Latins translated the term in both cases by subjectum. They spoke accordingly of the 'subject' of a science ${ }^{25}$.

Joáo Duns Scot (c. 1265-1308) parece oscilar entre os termos subjectum e objectum, preferindo este último:

Ora, falamos da matéria acerca da qual é a ciência, que é denominada por alguns 'sujeito da ciência', ou mais apropriadamente 'objeto', assim como também aquilo acerca do que é a virtude, é denominado apropriadamente 'objeto da virtude' e não 'sujeito'26.

Egídio Romano (c. 1243/7-1316), embora parta de uma caracterização do papel do sujeito bastante próxima do texto de Tomás de Aquino citado à nota 20, acaba identificando pura e simplesmente sujeito e objeto; identificaçáo já presente em Pedro de Auvergne (falecido em 1303) (COURTINE, 1990, p. 108-130, especialmente, p. 110-112 e 133). No entanto, o vocabulário referente ao sujeito e ao objeto da ciência parece à primeira vista continuar preservado por alguns comentadores de Tomás de Aquino ${ }^{27}$. No século XVII a tendência geral é considerar os termos como intercambiáveis, segundo o testemunho de Gonet (falecido em 1681):

Cumpre notar primeiro, com base em Capréolo (qu. 4 do prólogo, art. 1, concl. 2), que em qualquer ciência diferem de algum modo o sujeito e o objeto; com efeito, o objeto da ciência é a conclusão nela demonstrada, o sujeito, porém, é o que é sujeito nas conclusões e do qual são demonstrados alguns predicados ou afecções. No entanto, de acordo com o uso comum dos teólogos, o sujeito e o objeto sáo tomados comumente pelo mesmo e por isso perguntamos no título 'qual é o sujeito ou o objeto da teologia' ${ }^{28}$.

\footnotetext{
${ }^{25}$ Ver também (COURTINE, 1990, p. 10-15; DEWAN, 1981, p. 37-96).

${ }^{26}$ Quaestiones super Libros Metaphysicorum Aristotelis, liv. I, prólogo, no 32, p. 14, lins. 20-23.

${ }^{27}$ Ver os textos reunidos por Martin (1912, p. 12-14, n. 1). São citados Durando de Saint-Pourçain (falecido em 1322), Capréolo (falecido em 1444), Cajetano (1468-1534) e João de Santo Tomás (1589-1647).

${ }^{28}$ GONET, Clypeus theologiae thomisticae, Disputatio prooemiali, art. 3, parágr. 1; citado por (MARTIN, 1912).

Suarez nem discute mais o problema, ao que parece: "Uniuscujusque autem scientiae natura et dignitas ex objeto potissimum pendet, et ideo primum omnium inquirendum nobis est hujus doctrinae objectum
} 
A mesma preservação do vocabulário poderia ser observada em Guilherme de Ockham, apesar das diferenças entre sua concepção de ciência e a de Tomás de Aquino:

Há diferença entre o sujeito da ciência e o objeto da ciência, pois o sujeito da ciência é o sujeito da conclusão, mas o objeto da ciência é o que é sabido e termina o ato de saber. Ora, tal é a própria conclusão sabida. Assim, o sujeito é parte do objeto; e se for objeto, não é senão objeto parcial. (OCKHAM, 1967, v. I, p. 266, lin. 17-22) ${ }^{29}$.

NASCIMENTO, C. A. R. The two faces of science according to Thomas Aquinas. Trans/Form/Ação, Marília, v. 42, p. 57-74, 2019. Edição Especial.

ABstract: When dealing with science, Thomas Aquinas proves to have been influenced by the Posterior Analytics. He understands science either as a mental disposition or as a set of propositions organized according to their properties and their logical and epistemic relations.

KeY Words: Thomas Aquinas. Medieval philosophy. Science. Subject of science. Object of science.

\section{REFERÊNCIAS}

BOBIK, J. La doctrine de Saint Thomas sur l'individuation des substances corporelles. Revue Philosophique de Louvain, Louvain, v. 51, p. 5-41, 1953.

COURTINE, J.-F. Suarez et le système de la métaphysique. Paris: P.U.F., 1990.

DEWAN, L. Objectum: notes on the invention of a word. Archives d'Histoires Doctrinale et Littéraire du Moyen Age. Paris, v. 48, p. 37-96, 1981.

seu subjectum, quo cognito constabit facile quae sint hujus sapientiae munera, quae necessitas vel utilitas, et quanta dignitas." (Disp. Metaph., disp. I, Madri, Ed. Gredos, 1960, v. I, p. 208).

${ }^{29}$ Ver também (OCKHAM, 1967, v. I p. 247, lin. 12-250, lin. 12; COURTINE, 1990, p. 11; OCKHAM, 1973 p. 344).

Ao que saiba, não há uma exposição de conjunto satisfatória do tema aqui apresentado. Para o que se refere a Tomás de Aquino, uma boa apresentação, embora bastante rebarbativa, por se tratar de um típico curso romano da década de 50, encontra-se em Gagnebet (1958). Há pelo menos duas outras versóes anteriores. Nossa exposiçẫo deve bastante a este curso. 
GAGNEBET, R. De natura theologiae ejusque methodo juxta Sanctum Thomam. Romae: Pontificium Athenaeum Internationale "Angelicum", 1958.

GARDEIL, H. D. In: S. Th. D’Aquin. Somme Théologique, La Théologie, Ia, prologue et question 1. Paris: Cerf, 1997. p. 70, nota 16.

GEIGER, L.-B., Saint Thomas et la Métaphysique d'Aristote. In: Aristote et saint Thomas d'Aquin (Journées d'études internattionales. Chaire cardinal Mercier, 1955). Louvain: Publ. Univ. de Louvain; Paris: Béatrice Nawelaerts, 1957. p. 177. (Retomado em Philosophie et spiritualité. Paris: Ed. du Cerf, 1963. p. 127. V. 1).

JOÃO DUNS SCOT, Quaestiones super Libros Metaphysicorum Aristotelis. St. Bonaventure, N.Y: The Franciscan Institute, 1997.

KLUBERTANZ, G. P. St. Thomas and knowledge of the singular. The New Scholasticism, Washington, v. 26, p. 135-165, 1952.

MAC DONALD, S. Theory of knowledge. In: KRETZMANN, N.; STUMP, E. (ed.). The Cambridge Companion to Aquinas. Cambridge Univ. Press, 1996. p. 188-189, n. 13.

MARTIN, R.-M. L'objet integral de la théologie. Revue Thomiste, Toulouse, v. 20, p. 1214, 1912.

MAURER, A. Ockham's conception of the unity of science. Mediaeval Studies, Toronto, v. 20, p. 98-112, 1958.

MORRIS, N. A. The status of the dimensiones interminatae in the Thomasian principle of individuation. Aquinas, Vaticano, v. 39, p. 321-338, 1996.

NASCIMENTO, C. A. R. De Tomás de Aquino a Galileu. 2. ed. Campinas: Unicamp, IFCH, 1998.

NASCIMENTO, C. A. R. O caminho intermediário: alguns limites do conhecimento intelectual humano segundo Tomás de Aquino. Trans/Form/Ação, Marília, v. 19, p. 205210, 1996.

OCKHAM, G. Opera theologica. Ed. Inst. Francisc. St. Bonaventure, N Y: St.

Bonaventure University, 1967. V 1.

OCKHAM, G. Prólogo do comentário à física. In: Os pensadores. São Paulo: Abril, 1973. V. 8.

OWENS, J. The doctrine of being in the metaphysics: a study in the Greek Background of mediaeval thought. Toronto: Pont. Inst. of Mediaeval Studies, 1957.

ROBERT, J.-D. Eléments d'une définition analogique de la connaissance chez S. Thomas. Revue Philosophique de Louvain, Louvain, v. 55, p. 443-469, 1957.

SERENE, E. Demonstrative science. In: KRETZMANN, N. et al. (ed.). The Cambridge history of later medieval philosophy. Cambridge: Cambridge Univ. Press, 1984. p. 496-518. 
TOMÁS DE AQUINO. Suma de teologia. Tradução de Alexandre Correia. São Paulo: Fac. de Fil. "Sedes Sapientiae”, 1946. V. 1.

TOMÁS DE AQUINO: Scriptum super Sententiis. Edited P. Mandonnet. Paris: Lethielleux, 1929. Tomo I.

TOMÁS DE AQUINO. Scriptum super Sententiis. Distinção I-XXI. Editado por M. F. MOOS. Paris: Lethielleux, 1956. Tomo III.

TOMÁS DE AQUINO. Quaestiones disputatae de veritate. In: Sancti Thomae de Aquino opera omnia. Roma: Commissio Leonina, 1970. Tomo 22, 1, Fasc. 2.

TOMÁS DE AQUINO. Expositio Libri Posteriorum. In: Sancti Thomae de Aquino opera omnia. Roma: Commissio Leonina, 1989. Tomo I, 2.

TOMÁS DE AQUINO. Quaestiones de quodlibet. In: Sancti Thomae de Aquino opera omnia. Roma: Commissio Leonina, 1996. Tomo 25, 1.

TOMÁS DE AQUINO. Quaestiones disputatae de potentia. In: Quaestiones disputatae. Turim: Marietti, 1953. p. 7-276. V. 2.

TOMÁS DE AQUINO. Summa theologiae. Roma: Editiones Paulinae, 1962.

TOMÁS DE AQUINO In duodecim libros Methaphysicorum Aristotelis expositio. Turim: Marietti, 1950.

VAZ, H. C. L. Metafísica: história e problema. Sintese, Belo Horizonte, v. 21, n. 66, p. 395-406, 1994.

Recebido: 30/12/2019

Aceito: 30/12/2019 
NASCIMENTO, C. A. R. 